\title{
Professional development of graduate teaching assistants in faculty- like positions: Fostering reflective practices through reflective teaching journals
}

\begin{abstract}
Muriel Gallego ${ }^{1}$
Abstract: This study explores the outcomes of reflective journaling among novice Graduate Teaching Assistants during the initial stages of their professional development. It seeks to establish whether there were common concerns addressed in their journals and if different levels of reflection were achieved. By means of content analysis of 177 entries, nine common themes were identified. Among these, "methodology" and "classroom management" were the most prevalent. Three degrees of reflection were used to categorize the entries. Slightly over half of the entries achieved high levels of reflection, whereas $49 \%$ of the entries did not. Recommendations for teacher educators and facilitators of the professional development of graduate students are provided.
\end{abstract}

Keywords: Reflective journals, teaching journal, graduate teaching assistants, teacher training, professional development

\section{Introduction}

Despite efforts to implement training opportunities at American universities, Graduate Teaching Assistants (GTAs) still carry out their teaching appointments with an evident lack of preparation (Boyd \& Boyd, 2005; Hardré, 2005). Since the pre-service instruction GTAs receive is often brief and insufficient, their first encounter with pedagogical and theoretical training usually occurs simultaneously with their first teaching experience at the college level (VanValkenburg \& Arnett, 2000).

Even when frequently appointed to faculty-like positions, mainly due to their content knowledge, GTAs are often times not provided with the necessary tools to offer high-quality education to undergraduate students. It has been noted that the experience GTAs gain while teaching is nearly the only opportunity to advance their development as future professors (Austin, 2002; Luo, Grady, \& Bellows, 2001; Wise, 2011). The operationalization of reflective activities and exploratory endeavors that could instill in GTAs the desire to become reflective practitioners are typically circumscribed to the few occasions in which GTAs are required to engage in pedagogical training. Moreover, extensive professional development is rather insufficient and GTAs are faced with the challenge of trial and error, as well as independent exploration of instructional methods, which means that much of their preparation tends to happen incidentally (Boyd \& Boyd, 2005; Wise, 2011).

Since teaching is inherently a profession that requires ongoing reflection; students' needs analysis; and evaluation of outcomes, students and oneself; it is essential that GTA trainers facilitate various types of reflective activities that help novice and in-training teachers evaluate the results of instructional practice and acquire self awareness (Lee, 2005).

Journal writing, one means of fostering reflection, has been shown to be beneficial to the

\footnotetext{
${ }^{1}$ Ohio University, 225 Gordy Hall, Athens OH 45701, Department of Modern Languages, gallego@,ohio.edu
} 
development of those in the teaching field (Boyd \& Boyd, 2005; Genc, 2010; Hatton \& Smith 1995; Kaur \& Kaur, 2010; H. Lee, 2005, I. Lee, 2008; Maarof, 2010; Zeki, 2010, inter alia). Journaling is considered a useful tool for self-exploration and to evaluate the meaning one gives to teaching (Pratt, 2002). Teacher candidates, novice teachers and experienced professionals can, through reflection, create or adjust their teaching persona so that abstract theoretical knowledge interacts with the application of that knowledge. Reflective journaling can then enhance a teacher's practice by permitting the exploration of factors that could positively or negatively impact their instructional methods, raise awareness concerning their own biases and beliefs, allow more sensitive responses to students' needs and establish the necessary connections between theory and practice (Genc, 2010; Maarof, 2010).

This study explores reflective journaling among novice GTAs as a mean to enhance reflective teaching practices and seeks to establish whether there were common concerns addressed in their journals and if different levels of reflectivity (Lee, 2005) were achieved.

\section{Background}

A reflective journal is a potential avenue for raising awareness and enhancing the practice of experienced teachers as well as advancing the professional development of novice teachers. Implementing techniques that promote reflective teaching plays an important role in the development of novice teachers. It can have a positive impact in the professional growth of graduate students in faculty-like positions, which consequently has a twofold effect. It contributes to enhancing the quality of education received by undergraduate students and better prepares the future professoriate.

Reflective journals can be implemented in different contexts and the outcomes could therefore be diverse. While teacher-training programs often require journaling during the student-teaching period, it is also commonly assigned during classes taken before embarking on the teaching appointment (Numrich, 1996; Kaur \& Kaur, 2010). "In-service journals" can include self-studies and journaling of a volunteer nature, as opposed to journaling as a requirement for a class or a program (Genc, 2010; Jeffrey, 2007; Porto, 2008).

Pre-service teachers experience a disadvantage regarding the benefits of journaling. Given the nature of their position, they lack the ability to establish correlations between their incipient knowledge of theory and the application of theories in the classroom. Therefore, when required to write teaching journals, pre-service teachers are pushed to make predictions without yet having experience in their own classrooms. (Lai \& Calandra, 2000; Pedro, 2005; Yost, Sentner, \& Forlenza-Bailey, 2000).

Mainly because of lack of experience, much of the reflection that takes place in both "pre-service journal writing" and "in-service journal writing" tends to be merely descriptive and superficial in its level of analysis and it tends to lack the expected essence of reflection (Lai \& Calandra, 2007; Hatton \& Smith, 1995; Maarof, 2007; Pultorak, 1996). Reflective journaling and the quality of critical reflection can be fostered, improved, or even developed by providing: 1) trigger questions, 2) supervised scaffolding, 3) opportunities to share experiences, and 4) opportunities to connect theory to practice (Hatton \& Smith 1995; I. Lee, 2008; Pultorak, 1996, Zeki, 2010).

Concerned with the absence of true reflection in teaching journals, previous studies have investigated the various degrees of "reflectivity." For instance, Hatton and Smith (1995), describe four types of reflection. The first one is called "descriptive writing", and entails a

Journal of the Scholarship of Teaching and Learning, Vol. 14, No. 2, May 2014. 
description of a given situation or literature review. The second level is the "descriptive reflection" which adds some degree of true reflection. At this level, situations are described or analyzed from a personal perspective without any other interconnection. The third level incorporates a more elaborate type of reflective writing and it consists of "dialogic reflection" in which the analysis is still at the individual level. This level is considered dialogic due to the conversations one can have with oneself in order to explore possible reasons for a given situation. The highest level is "critical reflection" which incorporates contemplation of various causes a given situation, as well as its possible links to social, historical or political factors.

Contrary to the four levels proposed by Hatton and Smith (1995), Lee (2005) suggests a three-tiered categorization of critical reflection. All of Lee's levels imply some sort of reflection. Starting in the first level, even without resorting to alternative explanations, the writer interprets experiences. The recall level (R1) is considered a recollection in which the writer is able to interpret a situation based on the exploration of his/her own experiences. The Rationalization level (R2) occurs in the middle of the continuum, in which the writer begins to make connections between experiences and reasons for those experiences. This level implies a more elaborate reflection due to the fact that the writer is not only able to interpret a given situation but also to discover guiding principles. The highest level of reflection is constituted by the Reflectivity level (R3), in which an agenda can be clearly established, and the analysis of previous experiences serves now as a way to elaborate the necessary changes to improve future endeavors.

In the studies conducted by Lee (2005) and Hatton and Smith (1995), a gradual progression from lower to higher levels of reflection was seen as teachers were gaining experience and familiarity with the reflective process. However, Lee (2005) points out that even when reflecting on technical or practical issues, high levels of reflection can also be achieved, if the interpretation of such issues involves deep analysis and suggestions for improvement.

Implementing reflective journaling as an assignment for novice teachers is a useful way of fostering self-awareness and the evaluation of teaching techniques. It additionally provides the opportunity for developing the foundation for an ongoing reflective practice as the teacher advances in his/her career. While studies haven shown the benefits of reflective journaling among teachers in training, research that documents reflective journaling by GTAs is rather scarce. Therefore, the current study investigates the outcomes of reflective journaling among foreign language GTAs during their first semester of teaching at the university level. For that, the following research questions guided this investigation:

1. Are there common concerns shared by GTAs as indicated in their journals?

2. What level of reflectivity do their journal entries display?

\section{The study}

The journal entries analyzed were provided over the course of three years by graduate students enrolled in their first year of a Masters in Spanish in a public, American university. These students were also serving as graduate teaching assistants in faculty-like positions, as part of a multi-section lower-division Spanish course. There were both males and females, some were foreign-born $(n=10)$ native speakers of Spanish, and some $(n=16)$ were U.S.-born native speakers of English. Of the foreign-born GTAs, six were male and four were females, while nine male and seven females were U.S.-born. None of the participants had had previous experience teaching at the college level in the U.S., and very few had had limited experience teaching at the high school level in the U.S. $(n=4)$ and/or in other countries $(n=2)$ prior to beginning their 
teaching appointment as GTAs.

All of the GTAs had participated in a week-long orientation before meeting their classes on the first day of the semester. During their first year as graduate students, the GTAs enrolled in a semester-long Foreign Language Methodology class (in which the journals were produced) as well as a two-semester discussion workshop.

Reflective journaling constituted one of the assignments in the Methodology class, for which students were required to write two journal entries per week. It has been found that having guiding questions or trigger topics can yield more effective results, in terms of the quality of the reflection and the writer's commitment to the activity (Mariko, 2011; Maarof, 2007, Yost et al. 2000; Zeki, 2012). Given that the participants of this study were graduate students, it was expected that they had, to some extent, already developed the ability to critically reflect and to make connections between theory and practice. Additionally, it was considered that guiding questions could impose topics that might not be a true concern for every GTA. Therefore, there were no thematic constraints, guiding questions, or prompts. They were instructed to write about the development of their teaching persona, successful or challenging moments in and out the classroom, as well as difficulties or accomplishments concerning classroom management and teaching approaches. They were also encouraged (but not required) to incorporate reflections based on the class readings regarding theories of second language acquisition, second language teaching methodology and pedagogical practices. Lastly, they were allowed to write in English or Spanish.

In this case, scaffolding was conducted in the form of oral interaction with the professor/mentor and peers. After 4 days of regular class a "journal day" was scheduled. During "journal days" each student read aloud an entry while the professor identified common themes and guided the discussion based on those themes. Often times, the common themes were evident and students themselves were able to relate to fellow GTAs and the anecdotes described in the entries, whereas less frequently the professor established connections and guiding principles. The most challenging aspect of the "journal days" for the professor was helping students stay on task and facilitating a fruitful discussion instead having the class become a mere venting session. The scaffolding mainly consisted of supporting GTAs and offering solutions to their concerns as well as new ideas and alternative strategies to implement in the classroom.

\section{Data coding and analysis}

In order to ensure the validity of the data by triangulation and to eliminate the variable "group" as a confounding one, journal entries were collected from three different cohorts. Similarly, to avoid data contamination, participants were not informed of this research project until long after the course was completed. Permission for using journal entries was requested at least one year after the course was completed. Of the 26 GTAs who wrote reflective journals during those three academic years, fifteen of them volunteered their journals to be analyzed as data for this study. Further measures were taken to avoid any gender, age, previous experience or language bias: a research assistant (RA) copied the journals into anonymous electronic files and categorized them into three different groups, according to the semester in which they were produced. Then, the RA randomly selected five journals from each group and passed them to the researcher.

The data were evaluated by means of content analysis, a qualitative method that involves three stages: 1) identification, 2) coding, and 3) categorizing themes or patterns (Patton, 2002). 
The fifteen journals contained a total of 177 entries and 37,852 words. The average length of an entry was 21 lines, ranging from as short as three lines to as long as two pages. After primary analysis, recurrent themes were identified. If a theme was mentioned by two thirds of the writers, it was considered relevant, and was subsequently included in the analysis. The RA was also asked to identify recurrent themes, which were compared and contrasted with the ones identified by the researcher. Then, the tabulation of frequency was conducted for the identified recurrent themes. After establishing the common themes, the levels of reflectivity were analyzed, for which Lee's (2005) categorization was used. The procedure was to place each entry into one of the categories (Recall level R1, Rationalization level R2, or Reflectivity level R3) and to determine whether there were any entries that could correspond to more than one category. Categorization produced by the RA and the researcher were compared and contrasted until achieving consensus. After that, simple frequency calculations were conducted to establish which level of reflection was more prevalent.

\section{Results and discussion}

The content analysis approach allowed for the identification of nine common concerns and recognition of reflectivity dimensions.

"Methodology" was a the broadest category since it encompassed entries related to: 1) material read in the methodology class; 2) discussions that happened in the methodology class and that the GTAs reflected upon or connected to their teaching; 3) methods that the GTAs tried to implement in their own classroom; 4) activities implemented in class; 5) reflections about outcomes of activities implemented in class.

"Classroom management" included remarks regarding GTAs' ability (or lack thereof) to navigate classrooms duties such as: 1) creating student-centered vs. teacher-centered class; 2) maintaining discipline and respect towards instructor and peers; 3 ) motivating students.

"Satisfaction" comprised notes related to different degrees of satisfaction with various aspects of the writers' life as a graduate student or as a graduate teaching assistant, including: 1) feelings of joy, happiness, etc. concerning student performance and progress; 2) support offered by peers or supervisors; 3 ) own progress in the teaching profession.

"Frustrations with students" was mainly populated by general expressions of frustration, disappointment, and discontent or complaints related to students' behavior in or out of the classroom.

"Owning the class and instructor persona" refers to comments related to the development of the teacher persona, and included concerns related to: 1) graduate student-graduate teaching assistant dichotomy; 2) having or lacking authority; 3) having or lacking preparedness; 4) having or lacking self-confidence.

"Observation" included instances in which the writer commented on either observing a peer or being observed by a peer or a supervisor, as well as reactions specifically derived from observations.

"Grading" included comments concerning aspects such as: 1) difficulties with calculating grades; 2) frustrations with the length of the grading process; 3) student complaints about grading fairness or effectiveness.

"Time management" was related to the ability or lack thereof to manage time within the busy and demanding schedule of a graduate student who also has a teaching appointment. Time management in the classroom is included in the theme "classroom management". 
"Notes to self" covered remarks that included statements such as: 1) I ought to try [...]; 2) I should implement $[. .$.$] in the near future/next class/next week/soon; 3) brief self advice of$ the type: a) don't panic!, b) I need to rest/study/catch up/be patient/etc.

Results indicate that GTAs were most concerned about methodological issues $(\mathrm{N}=78$, $25 \%)$, followed by matters of classroom management $(\mathrm{N}=52 ; 17 \%)$. Satisfaction $(\mathrm{N}=43,14 \%)$ and frustrations with students $(\mathrm{N}=41,13 \%)$ were very close, followed by affirmation or lack thereof of classroom ownership and teaching persona. Frequency of the nine themes is presented in Table 1.

Table 1

Frequency of Common Themes

\begin{tabular}{lcl}
\hline & $N$ & $\%$ \\
\cline { 2 - 3 } Methodology & 78 & 25 \\
Classroom Management & 52 & 17 \\
Satisfaction & 43 & 14 \\
Frustrations with students & 41 & 13 \\
Owning the class & 33 & 10 \\
Notes to self & 22 & 7 \\
Observation & 21 & 7 \\
Grading & 18 & 6 \\
Time management & 7 & 2 \\
Total & 315 & 100 \\
& & \\
\hline
\end{tabular}

As shown in the entries analyzed, through the completion of reflective journals, first year GTAs were able to reflect of their own learning processes, shortcomings, and experiences both as instructors and graduate students. Most were able to develop plan of actions, whether with long-term goals or day-to-day strategies.

As shown in the entries analyzed, through the completion of reflective journals, first-year GTAs were able to reflect on their own learning process, professional responsibilities, shortcomings, and experiences both as instructors and graduate students. Moreover, as in Genc (2012), participants showed signs of improvement and change.

The first research question aimed to investigate whether there were common concerns among GTAs. What follows is a more detailed discussion of the two most frequent themes: Methodology and Classroom management.

As expected, methodological issues took priority over other themes. Given that writing reflective journals was assigned in a foreign language methodology class, it was predictable that GTAs would make remarks about techniques and activities implemented in their classrooms. Moreover, as novice language instructors, it was foreseeable that one important goal was for them to find out where they stood with regards to theories of second language acquisition and current methods and approaches. 
Within the theme "Methodology", many subthemes were identified, for example, selfcriticism and self-awareness concerning the effectiveness of activities and techniques ${ }^{2}$ :

What to do when an activity does not turn out well? I feel I put forth a lot of effort and I didn't accomplish much. Why is it that certain activities work out well and some fail? Is there a problem in the activity or is it something else? How can I avoid this to happen in other activities? But this day, as many other bad days, shall pass; and there is always a new day full of possibilities and opportunities for improvement.

I think I have gotten better. I keep learning how to do cooler and more interesting PowerPoints. I have also created a few good activities. Moreover, every day I try to see the PowerPoints of the other GTAs to look for ideas and to offer my advice.

In addition to comments about activities and teaching styles, these observations were often times connected to recalling certain discussions that had taken place in the Methodology class. GTAs were frequently able to make connections between these discussions and designing resources to implement new strategies in their own classes. The instructional decisions made by GTAs generated reactions in the students, which consequently triggered more reflection.

Yesterday in 540 [reference to Methodology class], we talked about the importance of varying activities, and the order in which the material is presented. My fellow GTAs and I concluded that we have to change the order in our lesson plans. [the professor] talked about the need for not being predictable to capture students' attention. I kept thinking about it, maybe my students are not motivated because I always do the same thing and follow the same steps. Maybe just changing the typical lesson plan organization will change the pace. I am going to try.

The last change I introduced was to remove vocabulary lists. For this, both the methodology class and our weekly workshop have contributed a great deal. They have helped me identify the classroom as the place to practice my new skills. My students immediately complained because what they want is vocabulary lists and to memorize everything. I often get upset if they complain, but I am now beginning to see that complaints are unavoidable and that everything is going in the right direction.

When thinking about methodological issues, some GTAs made connections between a specific reading and decisions made while planning lessons. Even when the entries included misconceptions or the GTAs' understanding of a given theory was not quite accurate, they represented, nonetheless, an attempt towards reflection.

I realize my teaching today was to a large extent informed by Lee \& VanPatten's Making communicative language teaching happen. After reading the chapter I

\footnotetext{
${ }^{2}$ No substantial modifications have been made to the excerpts. Names have been eliminated, as well as specific references to classes and professors. If an entry was written originally in Spanish, it was translated by the researcher and proofread by the RA. 
realized that, as a language instructor, I've been a culprit in my effort to implement the so-called communicative approach in my classroom. I therefore decided to try something new today. Students in pairs and in groups of 4 or 5 will do most of the activities in the form of a contest while I give guidelines. The outcome? $100 \%$ participation. I then realize, teaching a foreign language can really be fun not only for the students but also for the instructor.

I now think more about theories and methods, I reflect more on my use of input. How can I make it more "direct"? Is it comprehensible? A student told me that sometimes she does not understand what I say. If she does not understand, how will she develop her "interlanguage"? If a student does not understand, how many more feel the same way and don't say anything?

The second most frequent theme was that of Classroom Management. Many of the remarks made were related to discipline, motivation, and student engagement. The GTAs were faced with the reality of students' disinterest and lack of motivation, or even disrespect, and had difficulties understanding the reasons why students behaved that way. This led them to question their own teaching styles, themselves as people, their ability to manage a group, etc.

I notice how most of my students get involved in collaborative activities and appear very enthusiastic, but there is always a small group that does not want to work with classmates. Whenever they are required to interact those students try to hide and start doing something to avoid getting involved. If I tell them to interact, they do it, but I have to be constantly pushing and their attitude concerns me.

Last week I was worried about discipline, this week I am worried about motivation. I feel that I am not a fun person, and I have a hard time talking to others. I'd like to think that when I am teaching I behave differently but my demons still chase after me. Time will tell! At least I can already make eye contact and call them by their names. My new goal is having them feeling something other than boredom.

On the one hand, the attitude displayed by the students was useful in that it triggered these thoughts and encouraged the GTAs to evaluate, re-evaluate and push for change. On the other hand, it caused a great deal of frustration (another of the recurrent themes) and could have had a "backfire" effect. It appears that the GTAs may have been questioning or second-guessing themselves too extremely. While self-evaluation is positive as it can foster change and improvement, too much self-questioning and self-criticism can be detrimental since it can hinder the professional development process by instilling a sense of failure or lowering self-confidence. The development of skills such as using "teacher talk", time and space management, maintaining self-confidence, and creating of a positive learning atmosphere was noted by many:

Last week in class [in reference to the Methodology class] we talked about "teacher talk" and I am certainly concerned about this. I think I speak very slowly, that I use cognates and I form syntactically simple sentences, even if they do not sound $100 \%$ accurate, because I know they will understand it better that 
Gallego, M.

way. However, there are still many faces showing confusion and at this point I don't think that many students should be confused. I don't know if the problem is mine, maybe I think I am simplifying my input but in actuality I am not doing it. In any case, this is one of the things I have to improve.

As usual, classroom time management has been a bit of a problem. I finished 10 minutes before the hour. Luckily (as almost always) I had an extra activity. The issue is that the last 10 minutes of class seem to be torture, but today they were truly awake and they did not complain about the activity and worked very productively.

I am getting to know my students a little better and I feel this is helping the classroom atmosphere. Some days, especially at the beginning of class they are very quiet (like it's almost awkwardly quiet). So I am employing a few different strategies.

The GTAs revisited the concept of teacher-centered versus student-centered clases in their journals. Many of the challenges and concerns they faced were related to designing a student-centered class.

The review day was too boring and teacher-centered and I had to include so much information that time flew. The best day of the week was Wednesday, I had good activities and the students participated a lot. I can already see who are the students that don't want to get involved or the ones that do just because they have to, apart from those who truly want to learn (the latter group is, of course, very small). I think everything is getting better, but there is still much more room for improvement.

Ifeel a lot more comfortable in class now that we have spent a few days together and I brought new batteries for the clicker, so I can walk around the classroom, something that I really like. I can't stand being in the same place.

With regards to the second research question, findings show that many of the GTAs were able to produce entries with different degrees of reflection. Even though $46 \%$ of the entries were categorized as Recall level (R1), the remaining 29\% were Rationalization level (R2) and 10\% Reflectivity level (R3). In addition, although not so frequent, some entries were also found to fall under more than one category. Frequency of reflectivity levels is presented in Table 2 below.

Showing an incipient level of reflectivity has been interpreted as a sign of lacking the necessary preparation for critical reflection (Kaur \& Kaur, 2010; Mariko, 2011; Maarof, 2007); therefore, guiding questions or scaffolding of some sort has been recommended (Mariko, 2011; Maarof, 2007, Yost et al. 2000; Zeki, 2012). Yost et al. (2000) maintain that reflective writing, especially amongst novice or pre-service teachers, can only be developed if we guarantee "supervised practical experiences" and writers prove to have "a personally meaningful knowledge based in pedagogy, theories of learning, as well as social, political, and historical foundation to which they can connect their experiences" (47).

Journal of the Scholarship of Teaching and Learning, Vol. 14, No. 2, May 2014. 
Results show that GTAs were able to engage in reflection and that guiding questions are not essential to achieve deeper levels of reflectivity since almost half of the entries were categorized as R2 (Rationalization level) or R3 (Reflectivity level) or a combination of two levels of reflection: $\mathrm{R} 1+\mathrm{R} 2(8 \%)$ and $\mathrm{R} 2+\mathrm{R} 3(7 \%)$.

Table 2

Frequency of Reflectivity Levels

\begin{tabular}{lcc}
\hline & $N$ & $\%$ \\
\cline { 2 - 3 } & & \\
First level of Reflectivity (R1) & 85 & 46 \\
Second level of Reflectivity (R2) & 53 & 29 \\
Third Level of Reflectivity (R3) & 19 & 10 \\
First and Second Level Combined (R1+R2) & 14 & 8 \\
Second and Third Level Combined (R2+R3) & 12 & 7 \\
Total & 179 & 100 \\
& & \\
\hline
\end{tabular}

R2 level entries (29\%) display the writer's ability to interpret situations and to connect experiences that could seem fragmented at first. This allows the writer to establish generalizations and, consequently, guiding principles for improving their instructional techniques. For example:

I realized that I am becoming too structured when it comes to lesson planning. I noticed I don't like the days in which the structure of the class HAS to be different, like review days. I find it hard to plan in a flexible way, without hindering the quality and usefulness of the class. I like teaching. It is hard to manage time and to find out how many minutes to devote to each part. There are days in which nothing works out and I just want to sleep, rest, and forget about everything. Sometimes I wonder whether I am doing a good job. Whether I am fulfilling my responsibilities and what is expected of me. I try to determine whom I work for: do I need to feel accepted? Do I work for myself? Do I work for improvement? Everything I study, I learn, I know, benefits myself first. I can share it afterwards. Maybe what I need to do is: 1) do things without expecting a reward or an approval from others; 2) Focus, be disciplined.

Moreover, $10 \%$ of the entries were classified as Reflectivity level (R3), considered the highest degree of reflection a journal writer can achieve. These entries include comments about a particular goal and provide an in-depth analysis of a given experience from various standpoints.

The arguments and controversies about finding the "perfect approach" to second language acquisition is not surprising. Human language, as we all know, is as complex as human nature itself. In teaching a second language therefore, one needs to be well-informed about the various methodologies, be it skill or processoriented. Thanks to 540 [in reference to the Methodology class] and writing these journal entries I have been able to realize the importance of a solid theoretical 
background. It has become obvious that a good base of grammatical input is as vital as the communicative and the encouraging environment that is provided in the classroom. There should be a constant stream of "pushed output" activities, which serves as catalysts for high intake thereby facilitating proficiency. Teaching, I will say, is an art hence every individual instructor should be encouraged to adhere to their unique set of principles within prescribed guidelines. I am finding my way. The support from [The professor] and my fellow TAs has a great impact, I feel they are a big part of my improvement. I challenge myself with the creation of tasks and try to give the students ample opportunities for interaction. I see a great difference between the ideas I am given now through our class discussions and readings, and the ideas I was given while I was teaching high school. I was very used to drills and memorization, today I understand why interaction is fundamental.

The R1 level entries (49\%) also imply a degree of reflection. Although the most salient aspect of this level is the description of experiences and the interpretation is only based on these experiences, this type of entry still constitutes the first step towards deeper levels of reflection.

Today I started my fifth week. I explained the crisis in Spain, to raise awareness. I also explained possessives and I don't think I did a good job. Until now, I never realized how hard it is to explain my own language. I think I am overall doing fine. Last week I gave 26 oral exams. They did fairly well.

Many entries that appeared to be mere anecdotal descriptions, also referred to readings, teaching moments, or incidents with students, which shows that even when merely narrating or recalling, GTAs are still able to establish incipient connections and interpretations. One can speculate that the act of recalling and interpreting given situations, even when the interpretation can only be accomplished through one's own experiences and not through alternative explanations (Lee, 2005) is a valid method for self-exploration. If an answer cannot be found, proposing a question and the fact that a given situation triggered that particular question, holds a reflective value. According to Lee (2005), high levels of reflection can be achieved also when referring to practical issues, if the interpretation of such issues involves deep analysis and suggestions for improvement. This was frequently the case in the entries categorized as R1 in which practical issues were discussed. GTAs were able to provide interpretations or answers to their questions based on their own experiences and to self-provide ideas for new directions and self-improvement.

Further research could compare the effects of variables such as peer scaffolding, supervisor scaffolding, and professional background in order to determine a more precise impact of journaling on the development of reflectivity. Moreover, most studies of the effects of reflective journals have been conducted with a group of teachers or GTAs being trained for the same field; future research could compare GTAs in different fields to determine whether the recurrent concerns are shared, not only within but also among various academic disciplines.

Lastly, the advantage of implementing reflective journaling with GTAs extends beyond a mere class assignment. The GTAs themselves considered journaling an effective tool as it helped GTAs enhance their practice. Many participants, without being prompted to do so, commented on the journal assignment: 
Gallego, M.

I believe that everything that I wrote here is part of a process that goes beyond specific reflection concerning material read. I believe the main goal of the journal is to help us see our training process and development: our doubts, our frustration, our small victories.

I can't believe I am writing my last entry. Reading back I realize how much confidence I have gained and I enjoyed remembering some of my opinions and realizing how much my perspective has changed. My entries evolved from just commenting about what we did in 540 [in reference to the Methodology class] towards issues that concerned me or made me happy about my class, and "my kids". I have learned a lot about theories, methods and I have found the class and this assignment [journal writing] super productive. I am overall satisfied with my work and about becoming an instructor.

GTAs identified reflective journaling as a practice than can promote their integral growth through instilling in them the importance of being reflective practitioners.

I think this has been a learning process for everybody. I hope my students learned, and I know I have learned a lot from them. I also learned a lot about theories of second language acquisition and that helped me think what I do, what I do right, and what I need to do better. I also think that all of us have learned from our fellow GTAs and we have worked collaboratively. The "journal days" were a good way to know everybody shared the same concerns. All of them have been to me a great support system, if not a second family. Writing this journal helped me put all of these pieces together and realize how important all of this was.

I taught high school for 5 years before starting this program, I thought my training was sufficient, and my high school students always thanked me for my teaching skills. Writing this journal opened my eyes. I now realize how important it is to constantly evaluate myself. This has been a great way to "look at myself in the mirror". I feel I am now an improved version. I must confess I was a bit skeptical about the usefulness of this assignment, but after completing it, I decided that I will always keep a journal, this has helped me tremendously!

\section{Conclusion and implications}

This study investigated the effects of implementing reflective journaling as a way to enhance the opportunities for training and professional development of GTAs. It particularly focused on discerning common concerns discussed in reflective journals originally written as an assignment for a foreign language methodology class by first-year Master's students teaching elementary Spanish. In addition, it determined different levels of reflectivity achieved in the journal entries.

Through content analysis of the data, it was possible to establish recurrent themes. The findings indicate that even though GTAs commented on a fairly wide variety of topics, mostly related to teaching and professional development, the most persistent concerns were those of 
Methodology and Classroom Management.

One aspect of this study's results was particularly significant and differed from previous research (Mariko, 2011; Maarof, 2007, Yost et al. 2000; Zeki, 2012) GTAs displayed the ability to achieve high levels of reflection without having guiding questions or trigger topics, proven by the fact that a little over half of the entries were constituted by level R2, R3 or a combination of those. Findings also indicate that reflective journaling along with oral scaffolding was valued by the GTAs and contributed to interiorizing different methodologies and circumnavigating the difficulties of implementing these methodologies. It additionally provided an avenue to selfexploration, not only concerning the development of their teaching style but also, on occasion, related to issues of identity and personality.

The findings of this study and previous research have demonstrated that reflective journaling has an overall positive impact in the development of aspiring or novice teachers; however, less has been said concerning the advantages it presents to teacher educators. Along with Numrich (1996) and I. Lee (2008) this study suggest that the emphasis be placed not only on the benefits for pre-service or novice in-service teachers or GTAs but also on the possibility of considering journal entries as a tool for either needs analysis or evaluation of GTAs. It is then recommended that teacher educators (and the numerous titles this position can encompass in the case of GTAs trainers), value the virtues of critical reflection. Further research could explore whether GTA trainers can obtain information to better inform their decisions concerning the creation of new and more effective opportunities for GTA mentoring through the analysis of journal entries provided by their trainees.

This investigation contributed to advancing knowledge concerning the implementation of reflective journals during the initial stages of GTAs professional development. Results showed that by engaging in reflective journaling, first year GTAs were able to raise self-awareness concerning learning processes, shortcomings, and experiences both as instructors and graduate students.

\section{Acknowledgements}

I would like to thank all the GTAs who participated in the study. Special thanks go to Nyssa Knarvik, Betsy Partyka and Mary Jane Kelley for their invaluable help and comments. All errors remain my own.

\section{References}

Austin, A. (2002). Preparing he Next Generation of Faculty: Graduate School as Socialization. The Journal of Higher Education, 73(1), 94-122. doi: 10.1353/jhe.2002.0001

Boyd, J., \& Boyd, S. (2005). Reflect and Improve. Instructional Development Through Teaching Journal. College Teaching, 53(3), 110-114. doi: 10.3200/CTCH.53.3.110-114

Genc, Z. (2010). Teacher Autonomy Through Reflective Journals Among Teachers of English as a Foreign Language in Turkey. Teacher Development, 14(3), 397-409. doi: $10.1080 / 13664530.2010 .504028$ 
Gallego, M.

Kaur, Sidhu, G. \& Kaur, S. (2010). Pathways to Reflective Learning and Teacher Development: Insights from Teacher Trainees' Diaries. Malaysian Journal of Education, 35(1), 47-57.

Hardré. P. (2005). Instructional Design as a Professional Development Tool-of-Choice For Graduate Teaching Assistants. Innovative Higher Education, 30(3), 163-169. doi: $10.1007 / \mathrm{s} 10755-005-6301-8$

Hatton, N., \& Smith, D. (1995). Reflection in Teacher Education: Towards Definition and Implementation. Teaching and Teacher Education, 11(1), 33-49.

Lai, G., \& Calandra, B. (2007). Using Online Scaffolds to Enhance Preservice Teachers' Reflective Journal Writing: A Qualitative Analysis. International Journal of Technology in Teaching and Learning, 3(3), 66-81.

Lee, H. (2005). Understanding and Assessing Preservice Teachers' Reflective Thinking. Teaching and Teacher Education, 21(6), 699-715. doi: 10.1016/j.tate.2005.05.007

Luo, J, Grady, M., \& Bellows, L. (2001). Instructional Issues for Teaching Assistants. Innovative Higher Education, 25(3), 209-230. doi: 10.1023/A:1007603816555

Mariko, S. (2011). Student Teachers' Reflective Journals on Teaching Practice Experiences. Contemporary PNG Studies, 14, 67-83.

Maarof, N. (2007). Telling His or Her Story Through Reflective Journals. International Education Journal, 8(1), 205-220.

Numrich, C. (1996). On Becoming a Language teacher: Insights from Diary Studies. TESOL Quarterly, 30(1), 131-153. doi: 10.2307/3587610

Pedro, J. Y. (2005). Reflection in Teacher Education: Exploring Pre-Service Teachers' Meaning of Reflective Practice. Reflective Practice, 6(1), 49-66. doi: 10.1080/1462394042000326860

Pultorak, E. G. (1996). Following the Developmental Process of Reflection in Novice Teachers: Three Years of Investigation. Journal of Teacher Education, 47(4), 283-291. doi: $10.1177 / 0022487196474006$

Yost, D. S., Sentner, S. M., \& Forlenza-Bailey, A. (2000). An Examination of the Construct of Critical Reflection: Implications for Teacher Education Programming in the 21st Century. Journal of Teacher Education, 51(1), 39-49. doi: 10.1177/002248710005100105

VanValkenburg, J. \& Arnett. C. (2000). The Professionalization of Teaching Assistants: Can it be Accomplished?. Die Unterrichtspraxis, 33, 7-13. doi: 10.2307/3531057

Wise, A. (2011). Supporting Future Faculty in Developing Their Teaching Practices: an Exploration of Communication Networks Among Graduate Teaching Assistants. International Journal of Teaching and Learning in Higher Education, 23(2), 135-149. 
Gallego, M.

Zeki, C. (2012). The Importance of Guiding Questions in Reflective Journaling. Hacettepe University Journal of Higher Education, 2, 282-292.

Journal of the Scholarship of Teaching and Learning, Vol. 14, No. 2, May 2014. 